\title{
Competitive and Cooperative Torquoselectivity in the thermal ring opening of cyclobutene: A density functional insight
}

\author{
LAKSHMINARAYANAN AKILANDESWARI* and CHANDRASEKARAN PRATHIPA \\ Department of Chemistry, Sri Sarada College for Women (Autonomous), Salem 636 016, India \\ e-mail: akilchem@gmail.com
}

MS received 4 January 2015; revised 25 May 2015; accepted 26 May 2015

\begin{abstract}
The competition between the two electron donors $\left(-\mathrm{OCH}_{3}\right.$ and $\left.-\mathrm{OSiH}_{3}\right)$ have been studied by positioning them at geminal and vicinal locations. We have also studied the cis and trans geometrical isomerism at the vicinal location. Thermodynamic and activation parameters such as free energies have been computed to understand the potential energy surface of the reaction. Our computed activation hardness supports the proposed torquoselectivity. Further, Nucleus Independent Chemical Shift (NICS) was calculated at the ring centre of the transition state (TS) which additionally supports the torquoselectivity. The delicate preferences for the pathways have been substantiated through NBO interactions.
\end{abstract}

Keywords. 3-Substituted cyclobutenes; electrocyclic ring opening; torquoselectivity; aromaticity; DFT; NICS.

\section{Introduction}

It is well known that cyclobutenes undergo thermal conrotatory electrocyclic ring opening reaction to form butadiene. ${ }^{1}$ When cyclobutenes are substituted at $\mathrm{C} 3$ carbon there are two possible pathways of thermal ring opening viz either rotation of 3-substituent inward (in the direction of cleaving $\sigma$ bond) or rotation of 3-substituent outward (in the direction away from cleaving $\sigma$ bond). The former leads to cis product and the latter to the trans product. This stereoselectivity that occurs due to preferential direction of twisting of the breaking $\sigma$ bond is coined the term "Torquoselectivity". ${ }^{2}$ It was established by Houk and coworkers ${ }^{3-11}$ that most electron donating substituents tend to rotate outward and electron withdrawing ones rotate inward to have a stabilizing interaction with cleaving bond. Torquoselectivity is more an electronic phenomenon than steric and at times one may over ride the other. ${ }^{12}$ Following this, many works focused on torquoselectivity of silyl, ${ }^{13}$ stannyl, ${ }^{14}$ selenyl, ${ }^{15}$ germanyl ${ }^{16}$ and bory ${ }^{17}$ substituents at 3-position of cyclobutene. Recently, work relating to torquoselective ring opening of azetines, ${ }^{18}$ substituted azetines $^{19}$ have substantiated interaction of lone pair of nitrogen and $\pi *($ LUMO) of cyclobutene. It was found that unlike methyl, silyl substituent preferred to rotate inward ${ }^{20}$ because of its low lying LUMO which accepts electron density from HOMO of cyclobutene system.

\footnotetext{
*For correspondence
}

Also, the contrasteric behavior of silyl substituent has been explained by the negative hyperconjugative stabilization by Murakami et al. ${ }^{21}$ Inagaki et al. ${ }^{22}$ have proposed an orbital phase theory to explain torquoselectivity of electrocyclic reactions where they emphasize on the dominant role of geminal bonds in deciding the torquoselective routes.

It is well known that $-\mathrm{OCH}_{3}$ is an electron donating substituent and it tends to follow an outward rotation pathway. It is presumptively anticipated that $-\mathrm{OSiH}_{3}$, similar to $-\mathrm{OCH}_{3}$, should be outward directing. At the same time it is expected that owing to negative hyperconjugative tendency of silicon, the electron density over oxygen would be reduced of course not so much so as to alter the outward rotation. Therefore, in the present study we intend to reiterate the fact that $\mathrm{OSiH}_{3}$ is an outward rotating substituent, and as geminal bonds decide the stereoselectivity we would like to probe at how these $-\mathrm{OCH}_{3}$ and $-\mathrm{OSiH}_{3}$ would compete with one another in selecting the torquoselective pathways when they are geminally and vicinally substituted. Therefore, in the present study 3-/4- substituted cyclobutenes A-E are chosen (scheme 1) and their conrotatory electrocyclic ring opening (ERO) pathways have been studied. The two pathways of ring opening (Path I - $\mathrm{R}_{1}, \mathrm{R}_{4}$-directed inward and $\mathrm{R}_{2}, \mathrm{R}_{3}$-directed outward) (Path II- $\mathrm{R}_{1}, \mathrm{R}_{4}$-directed outward and $\mathrm{R}_{2}, \mathrm{R}_{3}$ directed inward) are possible. The transition states (TS) and products corresponding to both the pathways have been located. 


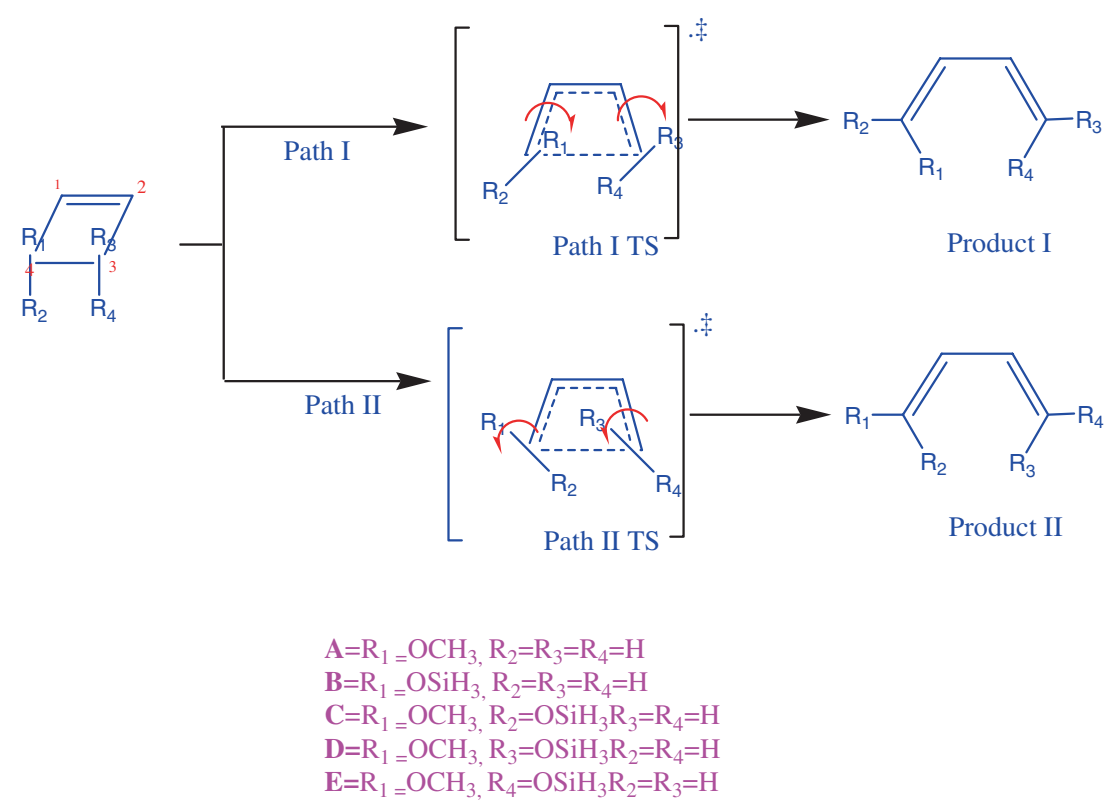

Scheme 1. Thermal Conrotatory Electrocyclic ring opening pathways of substituted cyclobutenes.

\section{Computational details}

All the stationary points and TSs were optimized at B3LYP ${ }^{23} / 6-31 G$ (d) level using Gaussian 98 software. ${ }^{24}$ The stationary geometries of reactants and products were characterized with real frequencies and TSs have one imaginary frequency with animation corresponding to conrotatory ring opening. Thermochemical and activation parameters like $\Delta \mathrm{E}, \Delta \mathrm{G}, \Delta \mathrm{H}, \Delta \mathrm{S}$ and $\Delta \mathrm{E}^{\ddagger}$, $\Delta \mathrm{G}^{\ddagger}, \Delta \mathrm{H}^{\ddagger}, \Delta \mathrm{S}^{\ddagger}$ have been calculated. In order to incorporate the effect of solvent, the reactant, product and TS energies were computed at PCM solvation model ${ }^{25}$ using benzene as solvent as all the experimental studies have employed non-polar solvents like benzene, xylene, etc. ${ }^{21,26,27}$ Natural Bond Orbital ${ }^{28}$ analysis for reactant, TS and product have been done at B3LYP/6-31G(d) level. $\mathrm{BFC}_{\mathrm{ave}}{ }^{29}$ which is the index of bond formation and cleavage has been computed using Wiberg bond indices. Nucleus Independent Chemical Shift ${ }^{30}$ (NICS) is an index of aromaticity has been calculated at B3LYP/6-311G+(d,p) level.

\section{Results and Discussions}

We have investigated five cyclobutenes with varying substituents (A to $\mathbf{E}$, scheme 1 ) at the $3^{\text {rd }}$ and $4^{\text {th }}$ positions. A, B and $\mathbf{C}$ are 3 -substituted cyclobutenes, whereas $\mathbf{D}$ and $\mathbf{E}$ are both 3 and 4-substituted cyclobutenes. In the systems $\mathbf{A}-\mathbf{E}$ under study, $\mathrm{OCH}_{3}$ or $-\mathrm{OSiH}_{3}$ or both and they may have syn or anti orientation in the reactant. All the possible isomers have been optimized and as there is not much variation in their energies, thus the most stable species has been considered for electrocyclic ring opening.

All the five species can undergo thermal conrotatory ring opening reaction. The transition states corresponding to inward (Path I) and outward (Path II) rotation of 3 -substituents are shown in figure 1 . In the case of $\mathbf{C}$ there are two substituents at $\mathrm{C}-3$ namely $-\mathrm{OCH}_{3}$ and $\mathrm{OSiH}_{3}$. When the former goes inward, the latter moves outward and vice versa. $\mathbf{D}$ and $\mathbf{E}$ have vicinal substitution of $-\mathrm{OCH}_{3}$ and $-\mathrm{OSiH}_{3}$ in cis and trans position, respectively. The thermodynamic parameters $(\Delta \mathrm{G}, \Delta \mathrm{H}$ and $\Delta S)$, activation parameters $\left(\Delta \mathrm{G}^{\ddagger} \Delta \mathrm{H}^{\ddagger}\right.$ and $\left.\Delta \mathrm{S}^{\ddagger}\right)$ and activation hardness $\left(\Delta \eta^{\ddagger}\right)^{18,31}$ are collected in table 1. From the table 1, it is clear that in all the reactions (A to E) both path (I and II) are exothermic. The activation enthalpy and free energy for each reaction are nearly equal emphasizing the least contribution from activation entropy (table 1). To monitor torquoselectivity, the difference between $\Delta \mathrm{G}^{\ddagger}$ of both the pathways $\left(\Delta \mathrm{G}_{\text {PathI }}^{\ddagger}-\Delta \mathrm{G}_{\text {PathII }}^{\ddagger}\right)$ are designated as $\Delta \Delta \mathrm{G}^{\ddagger}$ and are collected in table 1 . Focusing on the aspect of torquoselectivity, Path I which takes $-\mathrm{OCH}_{3}$ inward in system A has high activation barrier $(37.31 \mathrm{kcal} / \mathrm{mol})$ as compared to Path II (methoxy outward). This is consistent with the proposal that electron donors prefer outward rotation. Although other electron donating substituents have been verified to obey this outward directing torquoselectivity, the computational calculations for $-\mathrm{OCH}_{3}$ are not reported so far. Our calculated $\Delta \mathrm{G}^{\ddagger}$ is in excellent agreement with the experimental data of electrocyclic ring opening of 3-methoxy cyclobutene. $\left(\Delta \mathrm{G}^{+}=\right.$ $25 \mathrm{kcal} / \mathrm{mol}$ ). ${ }^{32}$ The two pathways (Path I and Path II) 


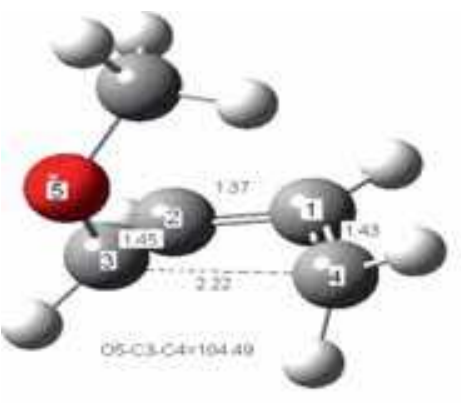

A I

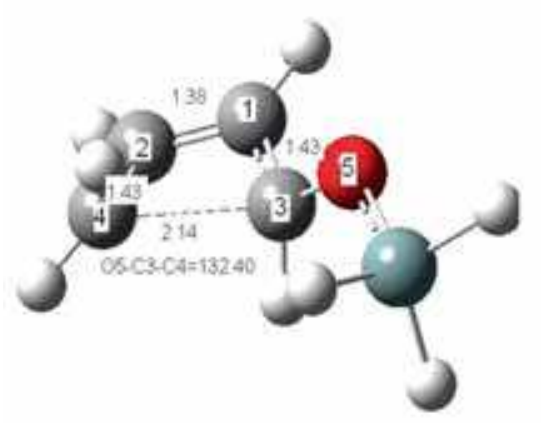

B II

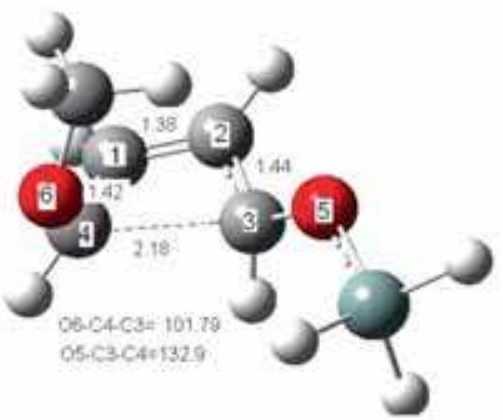

D I

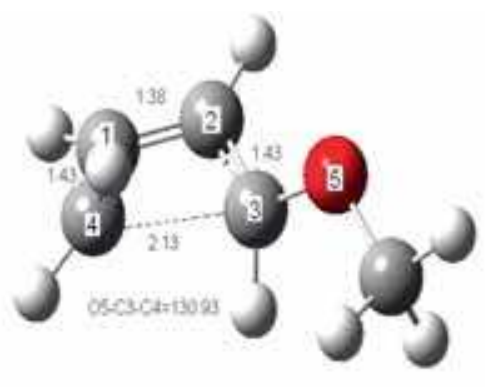

A II

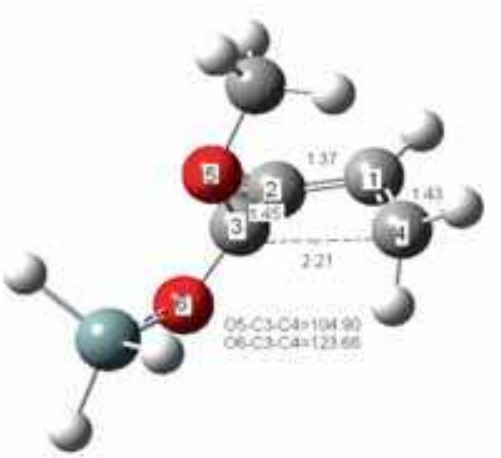

C I

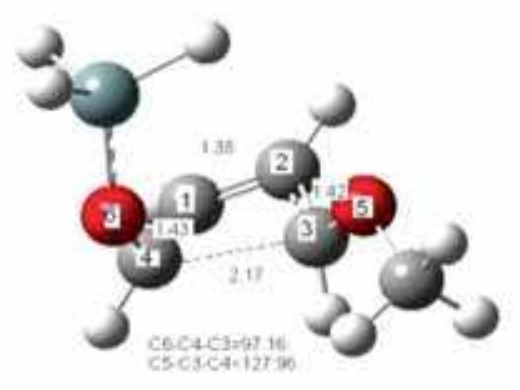

D II

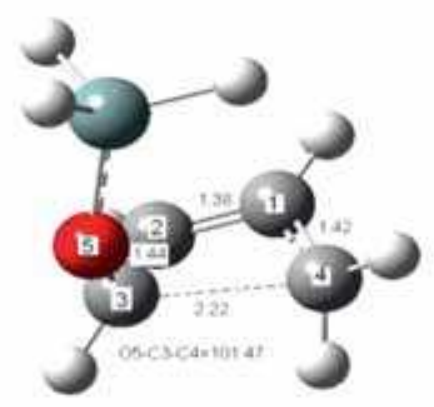

B I

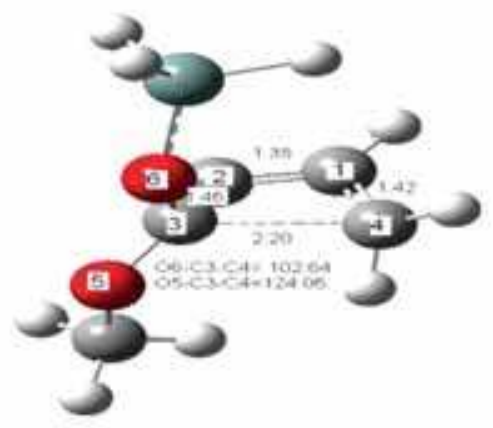

C II

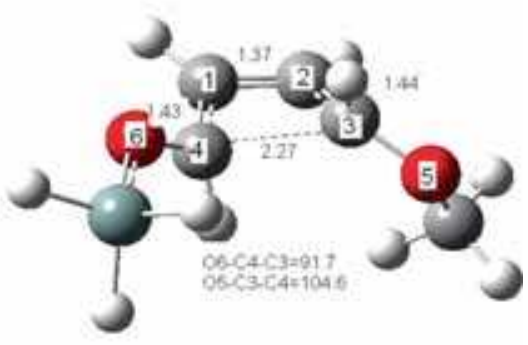

E I

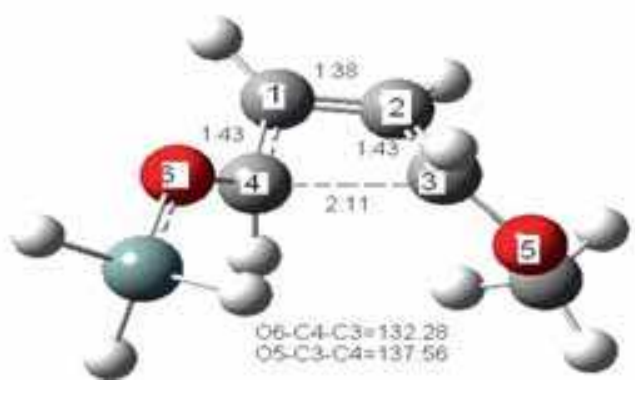

E II

Figure 1. Optimized Geometries of TSs for conrotatory electrocyclic ring opening of A-E at B3LYP/6-31G(d).

differ by around $14 \mathrm{kcal} / \mathrm{mol}$ which is similar to that reported by Houk et al. ${ }^{33}$ for 3- hydroxy substituent.

Similar to A, the reactant $\mathbf{B}$ prefers Path II (outward rotation) with $\Delta \Delta \mathrm{G}^{\ddagger}$ of $14.64 \mathrm{kcal} / \mathrm{mol}$. However, ring opening in $\mathbf{C}$ is intriguing as it poses a competition for both the outward directing substituent at C-3 position. During the conrotation, either $-\mathrm{OCH}_{3}$ goes inwards and $-\mathrm{OSiH}_{3}$ group moves outwards (Path I) or $-\mathrm{OCH}_{3}$ 


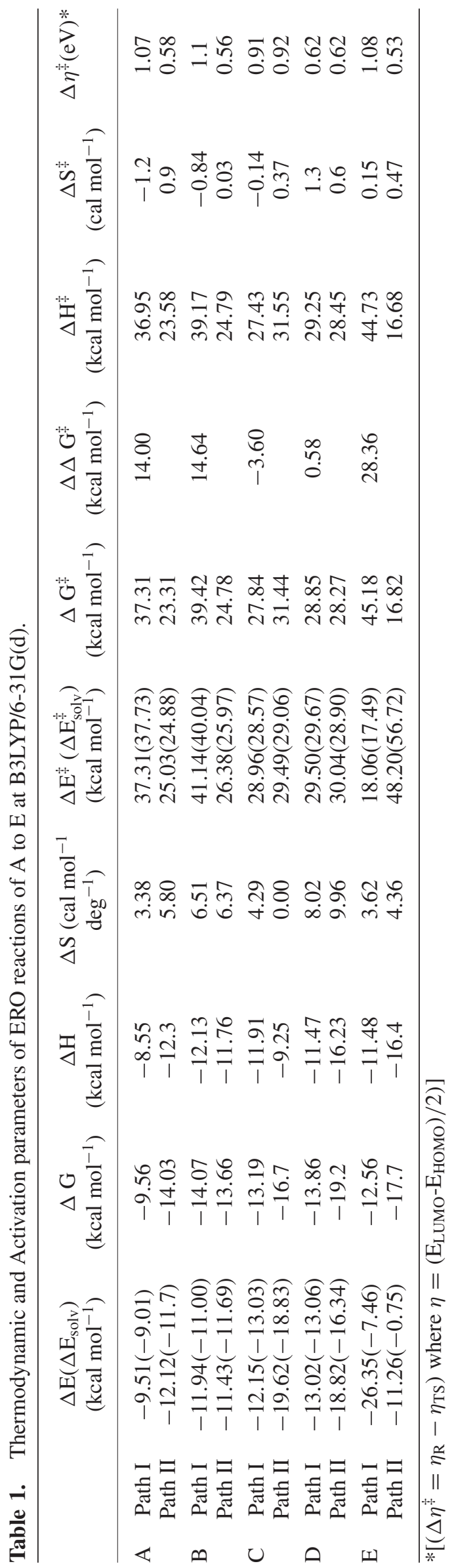

moves outward and $-\mathrm{OSiH}_{3}$ is forced inward (Path II). Our computed activation barriers show that $-\mathrm{OSiH}_{3}$ prefers to move outward thus forcing $-\mathrm{OCH}_{3}$ inwards, thus Path I is favoured to Path II. Within the two functional groups, $-\mathrm{OSiH}_{3}$ is more electron donating as compared to $-\mathrm{OCH}_{3}$ group, although the energy difference between the pathways $\left(\Delta \Delta \mathrm{G}^{\ddagger}\right)$ is only marginal (3.6 $\mathrm{kcal} / \mathrm{mol}$ ). Further, the increased barrier of the most feasible pathway in $\mathbf{C}$ (Path I) as compared to $\mathbf{A}$ (Path II) and $\mathbf{B}$ (Path II) is due to compelled inward rotation of an electron donor $-\mathrm{OCH}_{3}$.

In the case of $\mathbf{D}$ there is again a competition between $-\mathrm{OCH}_{3}$ in $\mathrm{C}-3$ and $-\mathrm{OSiH}_{3}$ in C-4 towards outward rotation. Surprisingly, both pathways are equally lying showing that both $-\mathrm{OCH}_{3}$ and $-\mathrm{OSiH}_{3}$ functional groups rotate inwards which are equally energetically unfavorable at vicinal location as compared to their geminal location $(\mathbf{C})$.

Among the two pathways, Path II is kinetically highly favored in $\mathbf{E}$ due to very low barrier. These variations emphasize that the preference of both electron donors is for rotating outward in ring cleavage. The difference in pathways $\left(\Delta \Delta \mathrm{G}^{\ddagger}\right)$ being $29.24 \mathrm{kcal} / \mathrm{mol}$ demonstrate exuberantly differentiating torquoselectivity. The low barrier for path II emphasizes the additive effect of both the outward rotating electron donating substituents facilitate the ring opening reaction.

\subsection{Activation hardness}

In general, if multiple pathways are available, the reaction proceeds through the pathway which involves less change in hardness (pathway that has much harder TS) which is indicated by less activation hardness $\left(\Delta \eta^{\ddagger}=\right.$ $\left.\eta_{\mathrm{R}}-\eta_{\mathrm{TS}}\right) .{ }^{18,29}$ We have computed the activation hardness $\Delta \eta^{\ddagger}$ (table 1) and the pathway preference follow the kinetic preferences which is based on activation free energy.

For $\mathbf{A}$ and $\mathbf{B}$, activation hardness is relatively low for Path II as compared to Path I. These are largely due to the crucial role played by frontier orbitals which modulate the preferential outward rotation of electron rich $-\mathrm{OCH}_{3}$ or $-\mathrm{OSiH}_{3}$ substitution. For systems $\mathbf{C}$ and $\mathbf{D}$, the activation hardness remains the same for both pathways indicating that frontier orbitals are much the same during inward rotation of both $-\mathrm{OCH}_{3}$ and $-\mathrm{OSiH}_{3}$ groups. Interestingly the equal activation hardness for Path I and Path II in the case of system $\mathbf{D}$ correlates well with nearly equal $\Delta G^{\ddagger}$ but there is a slight difference in system C.

\subsection{Natural Bond Orbital analysis ${ }^{26}$}

The hyperconjugative interactions of the above five reactions (A-E) have been studied through NBO second 
order perturbation studies (table 2). In all systems (A to E) the low energy pathway is stabilized more (by 28.08 to $36.4 \mathrm{kcal} / \mathrm{mol}$ ) than the other pathway. The lowering of $\sigma \mathrm{C}_{3}-\mathrm{C}_{4}$ has consequently led to higher population in these orbitals in the energetically favored pathway. In C, $\mathrm{C}_{3}-\mathrm{C}_{4}$ bond is nearly of equal energy in both pathways. The E2 energy in the table 2 shows increased hyperconjugative interactions for the preferred pathway. In systems $\mathbf{A}$ and $\mathbf{B}$ the interaction between geminal lone pair of oxygen in $-\mathrm{OCH}_{3}$ and $-\mathrm{OSiH}_{3}$ has increased during their outward rotation. This leads to the stabilization of the TS and favors the pathway. There are also some more stabilizing hyperconjugative interaction between $\pi \mathrm{C}_{1}-\mathrm{C}_{2} \rightarrow \sigma^{*} \mathrm{C}_{3}-\mathrm{C}_{4}$ and $\sigma \mathrm{C}_{3}-\mathrm{C}_{4} \rightarrow$ $\pi^{*} \mathrm{C}_{1}-\mathrm{C}_{2}$ whose magnitude is increased in the preferred outward rotation of $-\mathrm{OCH}_{3}$ and $-\mathrm{OSiH}_{3}$ group (Path II). In system $\mathbf{C}$, there is some synergism between the two geminal substitution $-\mathrm{OCH}_{3}$ and $-\mathrm{OSiH}_{3}$ and therefore, even when $-\mathrm{OCH}_{3}$ is directed inward the lone pair of oxygen is able to stabilize through LP $\mathrm{OCH}_{3} \rightarrow \sigma^{*} \mathrm{C}_{3}-\mathrm{C}_{4}$ interaction. Additionally, a similar $\mathrm{LP} \mathrm{OSiH}_{3} \rightarrow \sigma^{*} \mathrm{C}_{3}-\mathrm{C}_{4}$ interaction has probably facilitated Path I slightly more than path II. In $\mathbf{D}$, the $\mathrm{LP} \mathrm{OCH}_{3} \rightarrow \sigma^{*} \mathrm{C}_{3}-\mathrm{C}_{4}$ interaction in Path $\mathrm{I}$ is reduced $(28.09 \mathrm{kcal} / \mathrm{mol})$ more than in path I of $\mathbf{C}$ while LP $\mathrm{OSiH}_{3} \rightarrow \sigma^{*} \mathrm{C}_{3}-\mathrm{C}_{4}$ is large enough. In Path II, LP $\mathrm{OCH}_{3} \rightarrow \sigma^{*} \mathrm{C}_{3}-\mathrm{C}_{4}$ is much larger $(35.84 \mathrm{kcal} / \mathrm{mol})$ while $\mathrm{LP} \mathrm{OSiH}_{3} \rightarrow \sigma^{*} \mathrm{C}_{3}-\mathrm{C}_{4}$ is very less (15.34 $\mathrm{kcal} / \mathrm{mol}$ ). It is interesting to observe that in the presence of both $-\mathrm{OCH}_{3}$ and $-\mathrm{OSiH}_{3}$ geminal substituents, the $\mathrm{LP} \rightarrow \sigma^{*} \mathrm{C}_{3}-\mathrm{C}_{4}$ hyperconjugative interaction is relatively high whether inward or outward. But in vicinal location, there is reduction in the aforesaid interaction during inward rotation and the reduction is much large for $-\mathrm{OSiH}_{3}$ inward (table 2).

In $\mathbf{E}, \mathrm{LP} \mathrm{OCH}_{3} \rightarrow \sigma^{*} \mathrm{C}_{3}-\mathrm{C}_{4}$ interaction is nearly same in both pathways but there is a large increase in LP $\mathrm{OSiH}_{3} \rightarrow \sigma^{*} \mathrm{C}_{3}-\mathrm{C}_{4}$ interactions in Path II. This accounts for a much low barrier during ring opening and additive electronic effect of both the substituents.

From the Wiberg bond indices from NBO calculations, the bond formation $\left(\mathrm{BF}_{\mathrm{ave}}\right)$, bond cleavage $\left(\mathrm{BC}_{\mathrm{ave}}\right)$ and bond formation and cleavage average $\left(\mathrm{BFC}_{\mathrm{ave}}\right)$ have been computed and collected in table 3 . It is seen that the rate of cleavage is larger than formation which is reasonable for a ring opening reaction. $\mathrm{BFC}_{\mathrm{ave}}$ index shows that all the TSs are almost reactant-like and subtle difference created by the electronic effect of the substituents brings about slight changes in $\mathrm{BFC}_{\mathrm{ave}}$.

\subsection{Aromaticity criterion in deciding the pathway}

It is well known that all pericyclic transition states are aromatic and more the aromaticity of the TS lesser is the barrier. $^{34}$ Therefore in pursuit of effect of aromaticity in deciding the torquoselectivity, $\operatorname{NICS}(0)$ (at the ring centre) and NICS(1) (1 $\mathrm{A}$ away from ring centre) have been computed and collected in the table 3 .

In almost all the systems (A to $\mathbf{D}$ ), the most favored pathway has more aromatic TS which is indicated by more negative NICS(0) and (1). In $\mathbf{C}$ and $\mathbf{D}$, there is not much difference in NICS values for both the pathways. In $\mathbf{E}$, it is interesting that NICS value of Path I is high lying and is more negative than Path II which is favored energetically. Although both the TSs (Path I and Path II) are aromatic, the more negative NICS(0) and (1) for Path I may be due to the electron cloud of both the inward rotating oxygen. But this aromaticity exaltation is not sufficient enough to counterfeit the steric hindrance that the system may face during inward direction of bulky and electron releasing groups. Therefore, in $\mathbf{A}$ to $\mathbf{D}$, aromaticity cooperates with torquoselectivity. Interestingly, both are slightly in conflict in $\mathbf{E}$ and the steric factor dominates and couples with electronic factor (torquoselectivity), overriding the gain due to aromaticity exaltation at the TS to decide the pathway.

Table 2. Second order perturbation energies $\left(\mathrm{kcal} \mathrm{mol}^{-1}\right)$ of selected interactions in ERO reactions of A to E at B3LYP/6$31 \mathrm{G}(\mathrm{d})$ level.

\begin{tabular}{cccccc}
\hline & & $\sigma_{3}-\mathrm{C}_{3}-\mathrm{C}_{4} \rightarrow \pi * \mathrm{C}_{1}-\mathrm{C}_{2}$ & $\pi \mathrm{C}_{1}-\mathrm{C}_{2} \rightarrow \sigma * \mathrm{C}_{3}-\mathrm{C}_{4}$ & $\mathrm{LP}\left(-\mathrm{OCH}_{3}\right) \rightarrow \sigma * \mathrm{C}_{3}-\mathrm{C}_{4}$ & $\mathrm{LP}\left(-\mathrm{OSiH} \mathrm{H}_{3}\right) \rightarrow \sigma * \mathrm{C}_{3}-\mathrm{C}_{4}$ \\
\hline $\mathbf{A}$ & Path I & 29.19 & 20.36 & 30.65 & - \\
& Path II & 30.68 & 23.83 & 35.74 & - \\
$\mathbf{6}$ & Path I & 35.13 & 24.16 & - & 24.28 \\
& Path II & 31.51 & 25.7 & - & 31.22 \\
$\mathbf{C}$ & Path I & 27.26 & 19.18 & 35.65 & 27.18 \\
& Path II & 29.39 & 17.21 & 38.22 & 24.42 \\
$\mathbf{D}$ & Path I & 33.6 & 23.03 & 28.09 & 24.68 \\
& Path II & 36.4 & 23.18 & 35.84 & 15.34 \\
E & Path I & 33.28 & 20.52 & 33.33 & 2.84 \\
& Path II & 28.08 & 20.76 & 32.98 & 25.69 \\
\hline
\end{tabular}


Table 3. Bond formation and cleavage average $\left(\mathrm{BFC}_{\mathrm{ave}}\right) *$ during ERO reactions of A-E and Aromaticity index NICS $(0)$ and NICS(1).

\begin{tabular}{lcccccc}
\hline & & $\mathrm{BF}_{\text {ave }}^{*}$ & $\mathrm{BC}_{\text {ave }}^{*}$ & $\mathrm{BFC}_{\text {ave }}^{*}$ & NICS $(0)$ & NICS(1) \\
\hline A & Path I & 31.32 & 40.83 & 36.07 & -10.33 & -5.68 \\
& Path II & 36.95 & 41.68 & 46.42 & -12.15 & -13.58 \\
$\mathbf{B}$ & Path I & 39.6 & 45.54 & 42.57 & -8.1 & -2.21 \\
& Path II & 38.19 & 44.89 & 41.52 & -11.83 & -13.48 \\
$\mathbf{C}$ & Path I & 33.72 & 43.89 & 38.8 & -9.0 & -7.02 \\
& Path II & 34.48 & 47.08 & 41.7 & -9.56 & -8.98 \\
D & Path I & 38.75 & 46.87 & 42.81 & -13.06 & -6.36 \\
& Path II & 40.76 & 49.75 & 45.25 & -14.87 & -8.17 \\
E & Path I & 36.47 & 43.49 & 39.98 & -14.88 & -7.51 \\
& Path II & 36.08 & 43.33 & 39.71 & -7.32 & -5.73 \\
\hline
\end{tabular}

$*\left(\mathrm{BF}_{\mathrm{i}}\right.$ or $\left.\mathrm{BC}_{\mathrm{j}}=\mathrm{BO}_{\mathrm{i} \text { or } \mathrm{j}}^{\mathrm{TS}}-\mathrm{BO}_{\mathrm{i} \text { or } \mathrm{j}}^{\mathrm{R}} / \mathrm{BO}_{\mathrm{i} \text { or } \mathrm{j}}{ }^{\mathrm{P}}-\mathrm{BO}_{\mathrm{i} \text { or } \mathrm{j}}{ }^{\mathrm{R}} \times 100\right)\left(\mathrm{BFC}_{\mathrm{ave}}=\sum_{\mathrm{i}}(\mathrm{BFi}+\mathrm{BCj}) / \mathrm{n}\right)$.

\section{Conclusions}

Electron donating substituents prefer to rotate outward during the electrocyclic ring opening of 3-substituted cyclobutenes. We have investigated the competition between two substituents (electron donating $-\mathrm{OCH}_{3}$ and $-\mathrm{OSiH}_{3}$ ) of similar nature during their geminal, vicinal cis and trans location of 3-/4- substituted cyclobutenes. The electronic torquoselective effects were examined by computing kinetic and thermodynamic parameters by optimizing reactants, products and TS of path I and path II at the DFT level. When $-\mathrm{OCH}_{3}$ and $-\mathrm{OSiH}_{3}$ were singly substituted they prefer to rotate outward. When they are geminally located silyloxy succeeds in rotating outward forcing methoxy inwards. The difference between the in/out barrier is $4 \mathrm{kcal} / \mathrm{mol}$ suggesting $-\mathrm{OSiH}_{3}$ to be more electron donating than $-\mathrm{OCH}_{3}$. Interestingly, NBO interaction reveals some sort of synergism in geminally substituted system as the LP $\mathrm{OCH}_{3} \rightarrow \sigma^{*} \mathrm{C}_{3}-\mathrm{C}_{4}$ interactions remain large even during unfavourable inward rotation. But when the two substituents are vicinally (cis) located, the torquoselectivity diminishes as there seems to be not much gain or loss in driving any one of the substituent inward. While during vicinal trans location of substituents, the outward direction of both the substituents is highly favoured which could be substantiated not only based on steric reasons but also through electronic reasons. Again the cooperative synergism which is evident from $-\mathrm{OCH}_{3}$ and $-\mathrm{OSiH}_{3} \mathrm{LP}->\sigma^{*} \mathrm{C}_{3}-\mathrm{C}_{4}$ interaction of the substituents has reduced the barrier too low. Torquoselectivity prediction based on activation hardness agrees with kinetic predictions reiterating the frontier orbital control in these reactions. The more negative NICS for the preferred pathway for all the reactions except one confirmed the established fact that "more aromatic a pericyclic TS is, less is the barrier". In vicinal trans substitution, the aromaticity and torquoselectivity (electronic) contradict each other.

\section{Acknowledgements}

Authors are thankful for the critical comments of the reviewers which helped in refining the manuscript.

\section{References}

1. (a) Woodward R B and Hoffmann R 1970 In The conservation of orbital symmetry (Deerfield Beach FL: Verlag Chemie International); (b) Marvell E N 1980 In Thermal Electrocyclic Reactions (London: Academic Press)

2. Houk K N 1989 In Strain and Its Implications in Organic Chemistry de Meijere A and Blechert S (Kluwer Academic Publishers: Dordrecht) p. 25

3. Kallel E A, Wang Y, Spellmeyer D C and Houk K N 1990 J. Am. Chem. Soc. 1126759

4. Kallel E A and Houk K N 1989 J. Org. Chem. 546006

5. Thomas B E, Evanseck J D and Houk K N 1993 Isr. J. Chem. 33287

6. Evanseck J D, Thomas B E I V and Houk K N 1993 J. Am. Chem. Soc. 1154165

7. Houk K N, Spellmeyer D C, Jefford C W, Rimbault C G, Wang Y and Miller R D 1988 J. Org. Chem. 532125

8. Nakamura K and Houk K N 1993 Heterocycles 35631

9. Evanseck J D, Thomas B E IV, Spellmeyer D C and Houk K N 1995 J. Org. Chem. 607134

10. Kirmse W, Rondan N G and Houk K N 1984 J. Am Chem. Soc. 1067989

11. Rondan N G and Houk K N 1985 J. Am. Chem. Soc. 107 2099

12. Um J M, Xu H, Houk K N and Tang W 2009 J. Am. Chem. Soc 1316664

13. Murakami M, Miyamoto $\mathrm{Y}$ and Ito $\mathrm{Y} 2001$ Angew. Chem. Int. Ed. 40189

14. Murakami M, Miyamoto Y and Ito Y $2001 \mathrm{~J}$. Am. Chem. Soc. 1236441 
15. Murakami M and Hasegawa M 2004 Angew. Chem. Int. Ed. 434874

16. Murakami M, Hasegawa M and Igawa H 2004 J. Org. Chem. 69587

17. Murakami M, Usui I, Hasegawa M and Matsuda T 2005 J. Am. Chem. Soc. 1271366

18. Jaccob M, Sheeba J, Giri S, Venuvanalingam P and Chattaraj P K 2011 J. Phys. Org. Chem. 24460

19. Lopez S A and Houk K N 2014 J. Org. Chem. 796195

20. Lee S, Zhang X and Houk K N 2003 J. Am Chem. Soc. 1255072

21. Murakami M, Miyamoto Y, Hasegawa M, Usui I and Takanori M 2006 Pure Appl. Chem. 78415

22. Yasui M, Naruse Y and Inagaki S 2004 J. Org. Chem. 697246

23. Becke A D 1988 Phys. Rev. A. 38 309, Lee C, Yang W and Parr R G 1988 Phys. Rev. B. 37785

24. Frisch M J, Trucks G W, Schlegel H B, Scuseria G E, Robb M A, Cheeseman J R, Zakrzewski V G, Montgomery J A Jr, Stratmann R E, Burant J C, Dapprich S, Millam J M, Daniels A D, Kudin K N, Strain M C, Farkas O, Tomasi J, Barone V, Cossi M, Cammi R, Mennucci B, Pomelli C, Adamo C, Clifford S, Ochterski J, Petersson G A, Ayala P Y, Cui Q, Morokuma K, Malick D K, Rabuck A D, Raghavachari
K, Foresman J B, Cioslowski J, Ortiz J V, Stefanov B B, Liu G, Liashenko A, Piskorz P, Komaromi I, Gomperts R, Martin R L, Fox D J, Keith T, Al-Laham M A, Peng C Y, Nanayakkara A, Gonzalez C, Challacombe M, Gill P M W, Johnson B G, Chen W, Wong M W, Andres J L, Head-Gordon M, Replogle E S and Pople J A 1998 Gaussian 98, revision A.9 (Gaussian: Pittsburgh USA)

25. Tomasi J and Persico M 1994 Chem. Rev. 942094

26. Niwayama S, Wang Y and Houk K N 1995 Tetrahedron Lett. 366201

27. Aikawa K, Shimizu N, Honda K, Hioki Y and Mikami K 2014 Chem. Sci. 5410

28. Reed A E, Curtiss L A and Weinhold F 1988 Chem. Rev. 88899

29. Kalaiselvan A, Venuvanalingam P, Poater J and Sola M 2005 Int. J. Quantum. Chem. 102146

30. Jiao H J and Schleyer P v R 1998 J. Phys. Org. Chem. 11655

31. Zhou Z and Parr R G 1990 J. Am. Chem. Soc. 1125270

32. Dolbier W R, Henryk K J R, Houk K N and Sheu Chimin 1996 Acc. Chem. Res. 29477

33. Niwayama S, Adam K E, Spellmeyer D C, Sheu C and Houk K N 1996 J. Org. Chem. 612825

34. Evans M G 1939 Trans. Faraday Soc. 35824 